\title{
Caspase-Mediated Degradation of AMPA Receptor Subunits: A Mechanism for Preventing Excitotoxic Necrosis and Ensuring Apoptosis
}

\author{
Gordon W. Glazner, ${ }^{1}$ Sic L. Chan, ${ }^{1}$ Chengbiao Lu, ${ }^{1}$ and Mark P. Mattson ${ }^{1,2}$ \\ 1 Sanders-Brown Research Center on Aging and Department of Anatomy and Neurobiology, University of Kentucky, \\ Lexington, Kentucky 40536, and 2Laboratory of Neurosciences, National Institute on Aging, Baltimore, Maryland 21224
}

Activation of ionotropic glutamate receptors of the AMPA and NMDA subtypes likely contributes to neuronal injury and death in various neurodegenerative disorders. Excitotoxicity can manifest as either apoptosis or necrosis, but the mechanisms that determine the mode of cell death are not known. We now report that levels of AMPA receptor subunits GluR-1 and GluR-4 are rapidly decreased in cultured rat hippocampal neurons undergoing apoptosis in response to withdrawal of trophic support (WTS), whereas levels of NMDA receptor subunits NR1, NR2A, and NR2B are unchanged. Exposure of isolated synaptosomal membranes to "apoptotic" cytosolic extracts resulted in rapid degradation of AMPA receptor subunits. Treatment of cells and synaptosomal membranes with the caspase inhibitors prevented degradation of AMPA receptor subunits, demonstrating a requirement for caspases in the process. Calcium responses to AMPA receptor activation were reduced after withdrawal of trophic support and enhanced after treatment with caspase inhibitors. Vulnerability of neurons to excitotoxic necrosis was decreased after withdrawal of trophic support and potentiated by treatment with caspase inhibitors. Our data indicate that caspase-mediated degradation of AMPA receptor subunits occurs during early periods of cell stress and may serve to ensure apoptosis by preventing excitotoxic necrosis.

Key words: calcium; excitotoxicity; glutamate receptors; hippocampus; kainate; neurotrophic factor; NMDA
Activation of glutamate receptors may play important roles in the neuronal deaths that occur naturally during development of the nervous system and in various neurodegenerative disorders. Data implicate glutamate receptor activation in trophic factor withdrawal-induced death of cultured dopaminergic neurons (Schierle and Brundin, 1999) and in experimental models of stroke (Choi, 1992), Alzheimer's disease (Mattson et al., 1992; Guo et al., 1999), and amyotrophic lateral sclerosis (Rothstein, 1995; Kruman et al., 1999). Two major subtypes of ionotropic glutamate receptors mediate physiological and degenerative responses of neurons to glutamate (for review, see Seeburg, 1993). AMPA receptors are heterodimers composed of subunits GluR1GluR4; these receptors flux both $\mathrm{Na}^{+}$and $\mathrm{Ca}^{2+}$ and play a major role in glutamate-induced membrane depolarization and $\mathrm{Ca}^{2+}$ influx (Doble, 1995; Michaelis, 1998). NMDA receptors are heteromeric complexes formed by an obligatory NR1 subunit and one or more NR2 subunits designated NR2A-D (Gasic and Hollmann, 1992). NMDA channel opening is dependent on glutamate binding and previous membrane depolarization, which results in $\mathrm{Ca}^{2+}$ influx. Overactivation of AMPA and NMDA receptors, particularly under conditions of metabolic and oxidative stress, initiates a cascade of events involving protease activation and mitochondrial dysfunction that can result in cell death. Such "excitotoxic" neuronal death can manifest as either apopto-

\footnotetext{
Received Nov. 19, 1999; revised Feb. 22, 2000; accepted March 8, 2000.

This work was supported by the National Institute on Aging and by a fellowship to G.W.G. from National Institutes of Health. We thank Tom Bell and Lin Yan for technical assistance.

G.W.G. and S.L.C. contributed equally to this work.

Correspondence should be addressed to Mark P. Mattson, Laboratory of Neurosciences, National Institute on Aging, GRC 4F01, 5600 Nathan Shock Drive, Baltimore, MD 21224. E-mail: mattsonm@grc.nia.nih.gov.

Copyright (C) 2000 Society for Neuroscience $0270-6474 / 00 / 203641-09 \$ 15.00 / 0$
}

sis or necrosis depending on the intensity of receptor activation and other factors that are poorly understood (Ankarcrona et al., 1995; Staton and Bristow, 1997; Tenneti et al., 1998).

Apoptosis plays a central role in the death of neurons during development of the nervous system (Oppenheim, 1991) and is also implicated in neurodegenerative disorders such as stroke (Linnik et al., 1995; Mattson et al., 1999), Alzheimer's disease (Su et al., 1994; Guo et al., 1998), and Parkinson's disease (Tatton et al., 1998; Duan et al., 1999a). Among the biochemical events involved in apoptosis, activation of members of the caspase family of cysteine proteases is believed to play a particularly important role in coordinating the cell death process (Thornberry, 1997; Li and Yuan, 1999). Caspases cleave several different protein substrates that might play important roles in the execution of apoptosis. Examples of caspase substrates and the possible consequences of their cleavage include actin-cell shrinkage and membrane blebbing; poly ADP-ribose polymerase-nuclear DNA degradation; NF- $\kappa \mathrm{B}$ subunits-suppression of expression of survival-promoting genes; and Bcl-2-promotion of mitochondrial membrane permeability transition (for review, see Chan and Mattson, 1999). Activation of glutamate receptors can result in caspase activation, and caspase inhibitors can protect neurons against excitotoxicity (Du et al., 1997; Hara et al., 1997; Mattson et al., 1998; Tenneti et al., 1998). The specific caspase substrates that play critical roles in neuronal apoptosis are unknown. Because excitotoxic apoptosis is, by definition, unique to cells such as neurons that express ionotropic glutamate receptors, we tested the hypothesis that glutamate receptor proteins themselves are subject to caspase-mediated degradation. Our data indicate that caspases promote AMPA receptor degradation in neurons undergoing apoptosis and that such degradation plays an important 

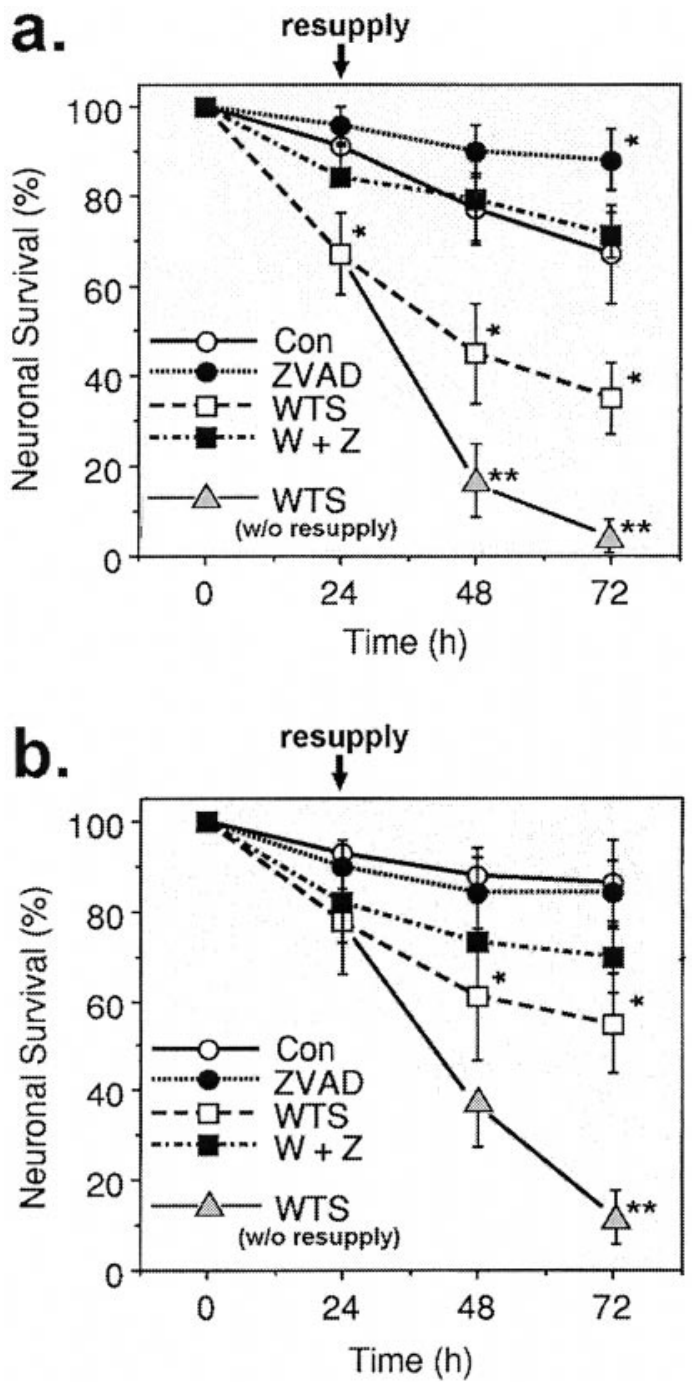

Figure 1. Progressive neuronal death of cortical and hippocampal neurons occurs after withdrawal of trophic support. Cortical $(a)$ and hippocampal $(b)$ neurons were incubated without (Con) or with zVAD-fmk (ZVAD), or deprived of trophic support for $24 \mathrm{hr}$ without (WTS) or with zVAD-fmk $(W+Z)$. At the end of this period, cells were incubated in complete Neurobasal medium for trophic resupply. Additional cultures were not resupplied trophic support. Neurons were photographed at 0,24 , 48 , and $72 \mathrm{hr}$ after original media change. Values are the mean and SEM of determinations made in four to six cultures. ${ }^{*} p<0.05$ compared with control; **p $<0.01$ compared with WTS value (ANOVA with Scheffe's post hoc tests).

role in "driving" neurons down an apoptotic pathway, thereby preventing necrosis.

\section{MATERIALS AND METHODS}

Primary neuronal cultures and experimental treatments. Hippocampi and neocortical hemispheres were removed from embryonic day 18 Sprague Dawley rats (Harlan Sprague Dawley, Indianapolis, IN). Cells were dissociated by mild trypsination and trituration as described previously (Mattson et al., 1995), seeded onto polyethyleneimine-coated plastic dishes or $22 \mathrm{~mm}^{2}$ glass coverslips, and incubated in Neurobasal medium containing B-27 supplements, $2 \mathrm{~mm}$ L-glutamine, $25 \mathrm{mg} / \mathrm{ml}$ gentamycin, 1 mM HEPES (Life Technologies, Gaithersburg, MD), and $0.001 \%$ gentamicin sulfate. All experiments were performed using 9- to 10-d-old cultures. Hippocampal cultures were used for all analyses except immunoblots that, because the analysis required relatively large numbers of neurons, were performed in samples from cortical cultures. Caspase inhibitors (zVAD-fmk, Calbiochem, La Jolla, CA; zDEVD-fmk and
WEHD-fmk, Enzyme Systems, Inc.) and staurosporine (Sigma, St. Louis, MO) were prepared as $500 \times$ stocks in dimethylsulfoxide.

Quantification of neuronal survival and apoptosis. Neuronal survival was quantified by established methods (Mattson et al., 1995). Briefly, viable neurons in premarked fields $(10 \times$ objective) were counted before experimental treatment and at specified time points thereafter. Neurons with intact neurites of uniform diameter and soma with a smooth round appearance were considered viable, whereas neurons with fragmented neurites and vacuolated soma were considered nonviable. To determine apoptotic cell death, cells were fixed, membranes were permeabilized, and staining with propidium iodide was performed. Cells were visualized under epifluorescence illumination $(340 \mathrm{~nm}$ excitation and 510 barrier filter) with a $40 \times$ oil immersion objective. The percentage of apoptotic cells was determined by nuclear morphological criteria; cells with condensed and/or fragmented DNA were considered apoptotic, whereas cells in which the DNA was distributed diffusely and uniformly throughout the nucleus were considered not apoptotic. For experiments using high levels of glutamate, in which cells die rapidly by necrosis, cell viability was determined by the trypan blue exclusion method.

Measurement of caspase activation. Caspase-3-like protease activity was assessed using a method described previously (Mattson et al., 1998). Briefly, cells were incubated for $20 \mathrm{~min}$ in the presence of biotinylated DEVD-CHO (a caspase substrate) and $0.01 \%$ digitonin. Cells were then fixed, incubated for $5 \mathrm{~min}$ in PBS containing $0.2 \%$ Triton X-100, and then incubated for $30 \mathrm{~min}$ in PBS containing Oregon Green-streptavidin (Molecular Probes, Eugene, OR). Images of fluorescence (corresponding to conjugates of activated caspase-3 with DEVD-biotin) were acquired using a confocal laser scanning microscope. Images were acquired using the same laser intensity and photodetector gain, to allow quantitative comparisons of relative levels of immunoreactivity in neurons. The average pixel intensity per cell body was determined using the Imagespace software provided by the manufacturer (Molecular Dynamics, Sunnyvale, CA); 8-16 neurons were analyzed per culture and determinations were made in at least three separate cultures.

Western blot analysis and immunocytochemistry. Separation and protein quantitation of AMPA receptor subunits by Western blotting was performed using methods similar to those reported previously (Cheng et al., 1995). Proteins in homogenates of cultured cells and synaptosomal membranes were separated by SDS-PAGE (10\% acrylamide) and transferred electrophoretically to a nitrocellulose membrane. The membrane was then incubated in blocking solution [ $1 \%$ normal goat serum in Tween Tris-buffered saline (TTBS)] followed by a $3 \mathrm{hr}$ incubation in TTBS containing primary antibody. The primary antibodies included rabbit polyclonal antibodies against AMPA receptor subunits (GluR1, GluR2/3, and GluR4) or NMDA receptor subunits (NR1, NR2A, and NR2B); each primary antibody was purchased from Chemicon (Temecula, CA). Membranes were then incubated for $1 \mathrm{hr}$ in a solution of peroxidase-labeled goat anti-rabbit IgG secondary antibody (1:4000 dilution in TBS). The blots were further processed using a chemiluminescence Western blotting kit (Boehringer Mannheim, Indianapolis, IN) according to the manufacturer's protocol. To confirm equal protein loading, blots were reprobed with a polyclonal goat anti-actin antibody (Santa Cruz Technology, Santa Cruz, CA). Images of blots were captured with a Umax 1200 S scanner, and densitometric analysis was performed using NIH image 1.47 software.

Cells were immunostained by sequential incubations in PBS containing primary antibody (anti-GluR4), PBS containing biotinylated antirabbit secondary antibody, and FITC-avidin using methods described previously (Guo et al., 1998). Images of GluR4 immunofluorescence were acquired using a confocal laser scanning microscope with a $40 \times$ oil immersion objective (488 nm excitation and $510 \mathrm{~nm}$ emission). All images were acquired using the same laser intensity and photodetector gain, to allow quantitative comparisons of relative levels of immunoreactivity in neurons. The average pixel intensity per cell body was determined using the Imagespace software provided by the manufacturer (Molecular Dynamics); 20-30 neurons were analyzed per culture, and determinations were made in at least four separate cultures. For doublelabeling studies, cells were exposed to primary antibodies [1:2000 dilution of goat polyclonal PSD-95 antibody (Santa Cruz) and 1:500 dilution of rabbit polyclonal anti-caspase-3 antibody (PharMingen, San Diego, $\mathrm{CA}$ )] overnight at $4^{\circ} \mathrm{C}$, followed by incubation for $30 \mathrm{~min}$ with a mixture of Texas Red-labeled anti-rabbit and biotinylated anti-goat secondary antibodies (Vector Laboratories, Burlingame, CA). Cells were then incubated for $30 \mathrm{~min}$ in the presence of avidin-fluorescein, and confocal images of cellular fluorescence were acquired using dual scanning mode. 

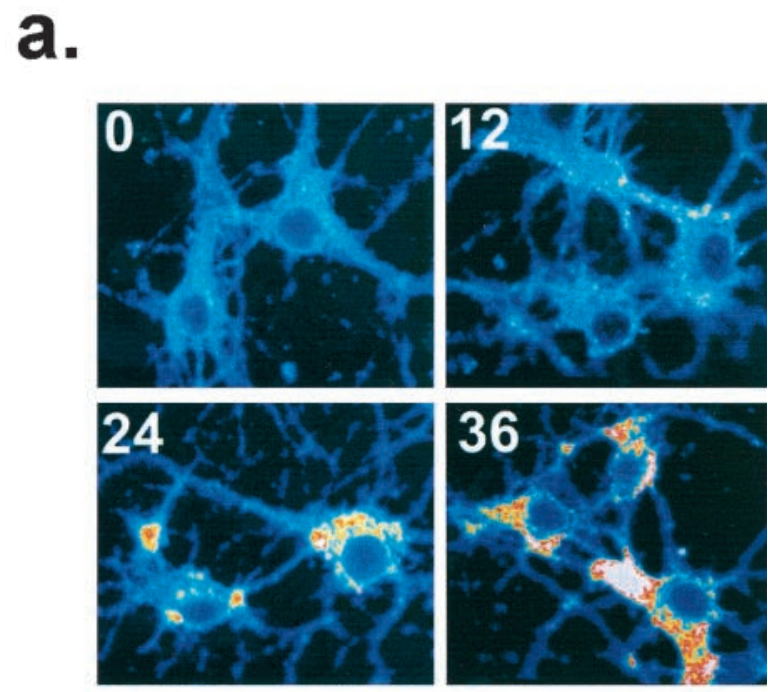

b.
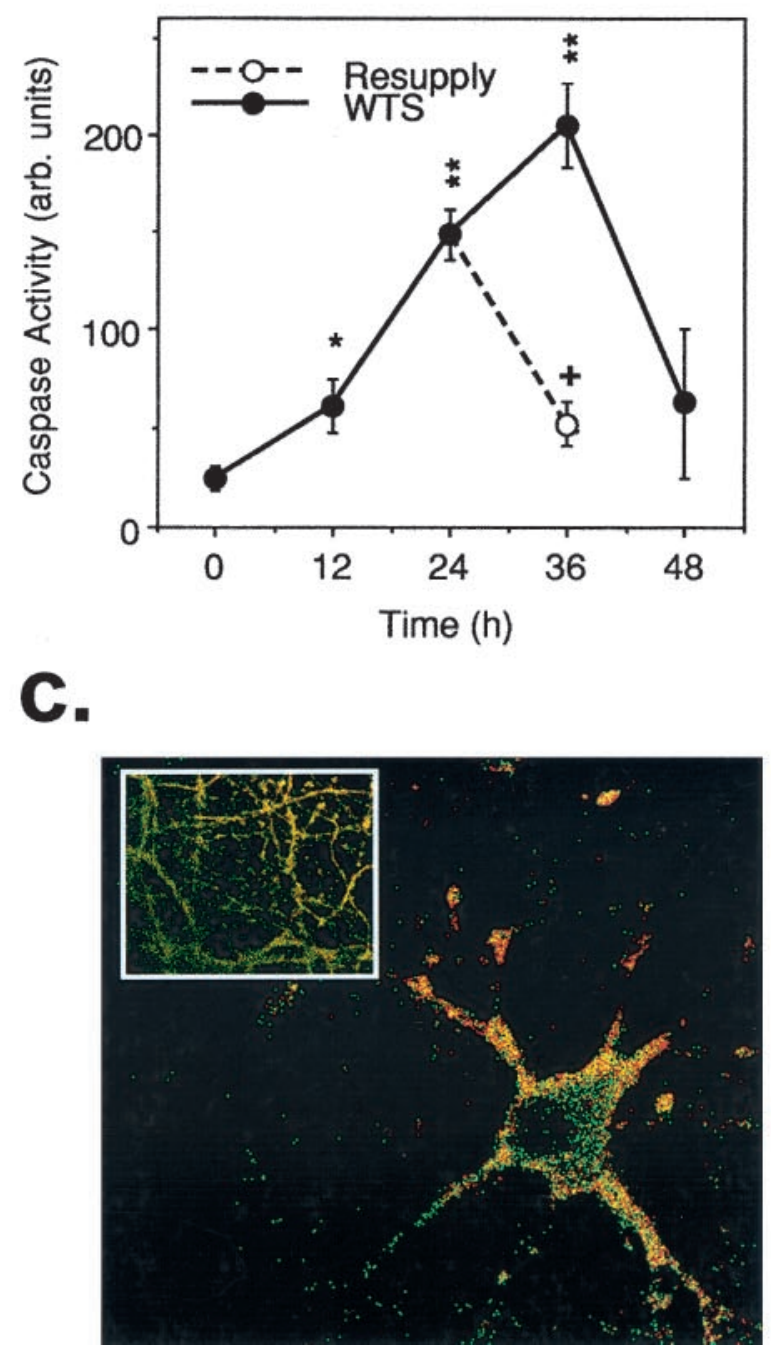

Figure 2. Caspase activation occurs after withdrawal of trophic support. $a$, Cellular fluorescence corresponding to conjugates of activated caspase- 3 with DEVD biotin were imaged using confocal microscopy at 0 , 12,24 , and $36 \mathrm{hr}$ after WTS. $b$, Relative levels of caspase activity were quantified (see Materials and Methods) at the indicated time points after
Synaptosome preparation and subcellular fractionation. The methods for isolation of synaptosomes from cerebral cortical tissue of adult rats were the same as those described previously (Keller et al., 1997; Mattson et al., 1998). Synaptosomes were diluted in Locke's buffer containing (in mM): $\mathrm{NaCl} 154, \mathrm{KCl} 5.6, \mathrm{CaCl}_{2}$ 2.3, $\mathrm{MgCl}_{2} 1, \mathrm{NaHCO}_{3}$ 3.6, glucose 5, HEPES $5, \mathrm{pH} 7.2$, for all experiments. Synaptosomes were dounce-homogenized in ice-cold breaking buffer and centrifuged, and plasma membraneenriched fractions were isolated from the supernatant by high-speed centrifugation $(100,000 \times g$ for $45 \mathrm{~min})$. To obtain caspase-enriched cytoplasmic extract, synaptosomes were incubated with $5 \mu \mathrm{M}$ staurosporine for $2 \mathrm{hr}$, a treatment we have previously shown to activate caspases in synaptosomes (Mattson et al., 1998). The synaptosomes were then exposed to three freeze-thaw cycles to disrupt membranes. The resultant mixture was centrifuged at $5000 \times g$ for $30 \mathrm{~min}$ to pellet organelles, and the supernatant was recentrifuged at $100,000 \times g$ to pellet membranes. The supernatant (cytosolic extract) was used as a source of activated caspases.

Quantification of intracellular $\mathrm{Ca}^{2+}$ levels. Intracellular free $\mathrm{Ca}^{2+}$ levels $\left(\left[\mathrm{Ca}^{2+}\right]_{\mathrm{i}}\right)$ were quantified by fluorescence imaging of the calcium indicator dye fura-2 as described previously (Mattson et al., 1995). Briefly, at designated time points after experimental treatments, cells were incubated for $40 \mathrm{~min}$ in the presence of the $2 \mu \mathrm{M}$ acetoxymethylester form of fura-2 (Molecular Probes). Immediately before imaging, dishes were washed twice in Locke's buffer. Cells were imaged on a Zeiss Axiovert microscope (40× oil immersion objective) coupled to an Attofluor imaging system. The average $\left[\mathrm{Ca}^{2+}\right]_{\mathrm{i}}$ in $10-14$ neuronal cell bodies per microscope field was quantified in three or four separate cultures per treatment condition. Experimental treatments were added to the bathing medium by dilution from $100-500 \times$ stocks.

\section{RESULTS}

\section{Characterization of cell death and caspase activation after withdrawal of trophic support}

To induce caspase activation and apoptosis, cortical and hippocampal cultures were subjected to withdrawal of trophic support (WTS) by incubation in Locke's buffer (Chan et al., 1999). In both cortical and hippocampal cultures, there was progressive death of neurons over a $72 \mathrm{hr}$ period, with $<10 \%$ of the neurons remaining at the $72 \mathrm{hr}$ time point (Fig. 1). However, when trophic support was resupplied at the $24 \mathrm{hr}$ time point, $\sim 40 \%$ of cortical neurons (Fig. 1a) and $60 \%$ of hippocampal neurons (Fig. 1b) survived through the $72 \mathrm{hr}$ time point. These data indicate that the cellular apoptosis program had not fated the majority of neurons to die after $24 \mathrm{hr}$ WTS, because they could still be spared by addition of trophic support.

Addition of the broad-spectrum caspase inhibitor zVAD-fmk to the cultures at the onset of WTS decreased neuronal death, demonstrating a requirement for caspase activation in the cell death process in this paradigm (Fig. 1). To establish the temporal relationship between caspase activation and neuronal death, we examined levels of caspase activity in hippocampal neurons at increasing time points after WTS. Confocal images of fluorescence associated with biotinylated DEVD-activated caspase conjugates revealed that activated caspases were localized in cell bodies and neurites, with particularly high levels of fluorescence

WTS with or without resupply of trophic support as indicated. Values are the mean and SEM of determinations made in at least three cultures. ${ }^{*} p<$ $0.05,{ }^{* *} p<0.01$ compared with the basal level; ${ }^{+} p<0.01$ compared with $36 \mathrm{hr}$ WTS (ANOVA with Scheffe's post hoc tests). $c$, Confocal laser scanning micrographs showing merged images of cultured hippocampal neurons that had been subjected to withdrawal of trophic support for 24 $\mathrm{hr}$ and then double-labeled with antibodies against activated caspase- 3 (red) and PSD95 ( green); yellow indicates sites of colocalization. The inset shows an enlarged image of dendrites. Note that there is considerable colocalization of active caspase- 3 and PSD95 in punctate sites in dendrites and near the plasma membrane in the neuronal soma. 
a.

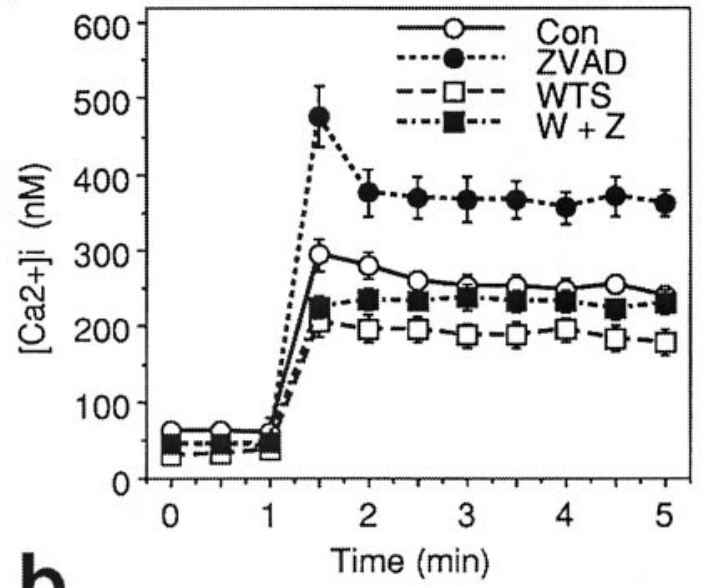

b.

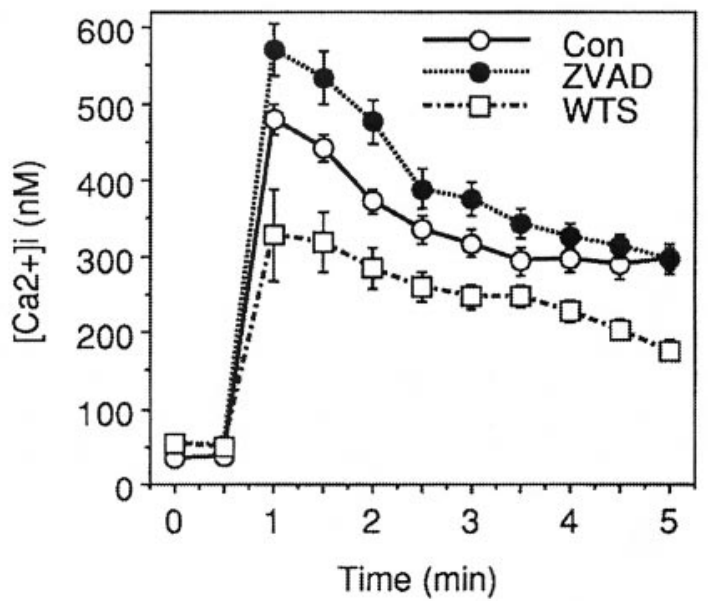

Figure 3. Evidence that caspase activation alters $\mathrm{Ca}^{2+}$ responses to glutamate. Hippocampal neurons were incubated without (Con) or with zVAD-fmk $(Z V A D)$, or deprived of trophic support for $24 \mathrm{hr}$ without $(W T S)$ or with $100 \mu \mathrm{M} z \mathrm{VAD}-\mathrm{fmk}(W+Z)$. At the end of this treatment, the $\mathrm{Ca}^{2+}$ indicator dye fura- 2 was added to cells for $30 \mathrm{~min}$. [ $\mathrm{Ca}^{2+}$ ]i was quantified before and after exposure to either $100 \mu \mathrm{M}$ glutamate $(a$, glutamate added at the 1 min time point) or $50 \mu \mathrm{M}$ kainic acid and $20 \mu \mathrm{M}$ MK-801 ( $b$, kainic acid added at the $1 \mathrm{~min}$ time point). Values are the mean and SEM of determination made in eight cultures (10-20 neurons assessed per culture). Statistical comparisons (peak calcium response): $a$, zVAD versus control $(p<0.01)$; WTS versus control $(p<0.05)$; $\mathrm{W}+\mathrm{Z}$ versus zVAD $(p<0.01)$; $b$, zVAD versus control $(p<0.05)$; WTS versus control $(p<0.01)$. ANOVA with Scheffe's post hoc tests.

being present in perinuclear regions (Fig. 2a). Quantification of caspase activity showed that levels of activated caspases were significantly increased within $12 \mathrm{hr}$ of WTS and continued to increase through $36 \mathrm{hr}$ (Fig. $2 b$ ). At the $48 \mathrm{hr}$ time point, levels of activated caspases decreased, presumably as a consequence of cell death.

To determine whether caspases are in fact present in the appropriate subcellular location to have access to AMPA receptor subunits, we performed double-label immunostaining analyses using antibodies against activated caspase- 3 and the postsynaptic density protein PSD95 (Kennedy, 1997). We chose PSD95 for these analyses because postsynaptic densities are structures in dendritic spines where AMPA receptor subunits are known to be highly concentrated. Examination of the double-labeling images revealed a high level of colocalization of caspase- 3 immunoreac- tivity and PSD95 immunoreactivity in dendrites and the cell body (Fig. 2c).

\section{Caspase activation after an apoptotic stimulus modifies neuronal sensitivity to glutamate}

Neurons in mature cortical and hippocampal cultures express both AMPA and NMDA receptors, and activation of these receptors appears to play roles in both apoptosis and necrosis after exposure to various insults (Mattson et al., 1993; Cheng et al., 1995; Larm et al., 1997; Tenneti et al., 1998). Activation of glutamate receptors may contribute to neuronal death in paradigms involving reduced trophic factor signaling (Caldero et al., 1997), and several different neurotrophic factors can protect cultured hippocampal and cortical neurons against excitotoxic insults (Mattson et al., 1989; Cheng and Mattson, 1991), suggesting a role for glutamate receptor activation in the modulation of cell death after WTS. To determine whether caspase activation plays a role in modifying neuronal responses to glutamate after an apoptotic insult, we measured $\mathrm{Ca}^{2+}$ responses to glutamate in hippocampal neurons after WTS in the absence or presence of zVAD-fmk. As expected from previous studies (Krieglstein et al., 1996; Xi and Ramsdell, 1996), the elevation of $\left[\mathrm{Ca}^{2+}\right]_{i}$ in response to AMPA receptor activation was suppressed when voltage-dependent $\mathrm{Ca}^{2+}$ channels were blocked with nimodipine (data not shown). The $\mathrm{Ca}^{2+}$ response to glutamate was significantly attenuated in neurons at $24 \mathrm{hr}$ after WTS, and addition of zVAD-fmk to cultures after WTS partially restored the $\mathrm{Ca}^{2+}$ response to glutamate (Fig. 3a). Treatment of cultures with zVAD-fmk for $24 \mathrm{hr}$ resulted in a highly significant increase in both the peak and sustained $\left[\mathrm{Ca}^{2+}\right]_{\mathrm{i}}$ increase (Fig. $3 a$ ). When AMPA receptors were selectively activated by addition of kainate in the presence of the NMDA receptor antagonist MK-801, the amplitude of the peak $\mathrm{Ca}^{2+}$ response was significantly reduced in neurons that had been subjected to WTS compared with neurons in control cultures (Fig. $3 b$ ). In contrast, the $\mathrm{Ca}^{2+}$ response to AMPA receptor activation was significantly increased in neurons treated for $24 \mathrm{hr}$ with zVAD-fmk. Acute application of zVADfmk (30 sec before addition of glutamate) did not affect the calcium response (data not shown), indicating that zVAD-fmk does not directly affect receptor function.

We next quantified neuronal survival after exposure to glutamate in cultures that had been subjected to WTS for $24 \mathrm{hr}$ in the absence or presence of zVAD-fmk. In one set of experiments we used trypan blue to identify necrotic neurons. Exposure of cultures that had not been subjected to WTS or zVAD-fmk treatment to a high concentration of glutamate $(500 \mu \mathrm{M})$ caused rapid necrosis such that $>80 \%$ of the neurons were trypan blue-positive within 6 hr (Fig. $4 a$ ). In contrast, $>40 \%$ of the neurons survived exposure to $500 \mu \mathrm{M}$ glutamate in cultures that had been subjected to WTS. Treatment with zVAD-fmk significantly exacerbated necrotic neuronal death induced by glutamate in cultures that either had or had not been subjected to WTS (Fig. 4a). These data suggested that caspase activation suppresses excitotoxic necrosis.

We next subjected neurons to WTS for $24 \mathrm{hr}$ and then exposed them to a lower concentration of glutamate $(10 \mu \mathrm{M})$, which results in delayed neuronal death that manifests as apoptosis (Duan et al., 1999b) for an additional $24 \mathrm{hr}$. Approximately 50\% of the neurons died within $24 \mathrm{hr}$ of exposure to $10 \mu \mathrm{M}$ glutamate, whereas $60 \%$ of the neurons died within 48 hr of WTS (Fig. $4 b$ ). Combined exposure to glutamate and WTS resulted in a highly significant increase in neuronal death compared with cultures 


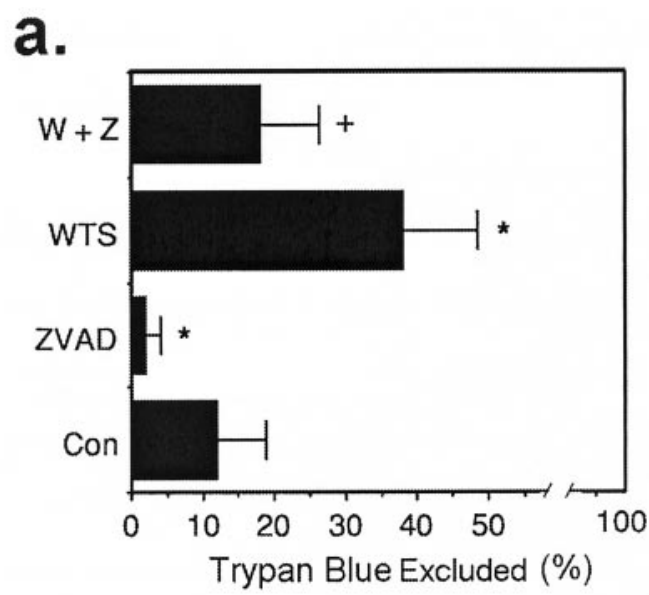

b.
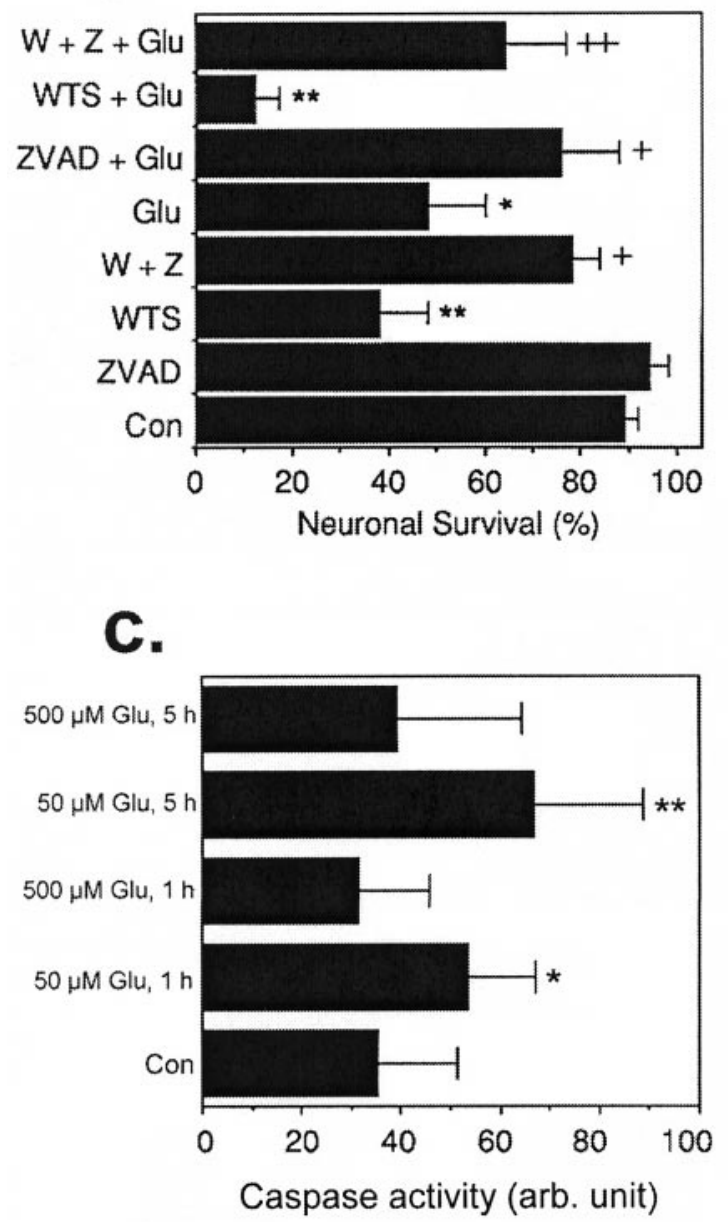

Figure 4. Analysis of the roles of caspase activation in glutamateinduced apoptosis and necrosis. $a$, Untreated control hippocampal culture without (Con) or with zVAD-fmk (ZVAD), and cultures deprived of trophic support for $24 \mathrm{hr}$ without (WTS) or with zVAD-fmk $(W+Z)$ were exposed to $500 \mu \mathrm{M}$ glutamate for $6 \mathrm{hr}$. Neuronal survival was assessed by the trypan blue exclusion method. $b$, Untreated control hippocampal cultures without (Con) or with zVAD-fmk $(Z V A D)$, and cultures deprived of trophic support for $24 \mathrm{hr}$ without $(W T S)$ or with zVAD-fmk $(W+Z)$ were exposed to $10 \mu \mathrm{m}$ glutamate in Locke's buffer for an additional $24 \mathrm{hr}$, and neuronal survival was determined by morphology-based analysis. Values are the mean and SEM of determinations made in eight cultures. ${ }^{*} p<0.05,{ }^{* *} p<0.01$ compared with control cultures; ${ }^{+} p<0.05,{ }^{++} p<$ 0.01 compared with corresponding group without zVAD-fmk (ANOVA exposed to either insult alone such that $90 \%$ of the neurons died during the course of the experiment. Treatment with zVAD-fmk afforded nearly complete protection against cell death induced by WTS and glutamate alone or in combination (Fig. 4b), indicating a requirement for caspase activation in the cell death process. Thus, although WTS can significantly inhibit glutamate (500 $\mu \mathrm{M}$ )-induced necrosis by a caspase-mediated mechanism, it exacerbates excitotoxic apoptosis at later time points.

\section{Withdrawal of trophic support results in caspase- mediated degradation of AMPA receptor subunits}

The data to this point indicated that caspases can modify neuronal sensitivity to glutamate and may thereby influence the mode of cell death, suppressing necrosis and promoting apoptosis. One possible mechanism whereby caspases might modulate glutamate responses is by affecting glutamate receptor subunits. We therefore determined whether levels of AMPA and/or NMDA receptor subunits are changed after WTS and/or treatment with zVAD-fmk. Western blot analyses were performed on homogenates of control cultures and cultures subjected to WTS in the absence or presence of zVAD-fmk using antibodies against different AMPA (GluR1, GluR2/3, and GluR4) and NMDA (NR1, NR2A, and NR2B) receptor subunits. WTS resulted in a dramatic decrease in levels of full-length GluR4, to $<25 \%$ of control values, within $24 \mathrm{hr}$ (Fig. 5a-c). Levels of GluR1 and GluR3 were also significantly decreased after WTS. Cotreatment of neurons with zVAD-fmk prevented the decreases in levels of each AMPA receptor subunit after WTS (Fig. 5a,c). Treatment of cultures with zVAD-fmk alone (without WTS) resulted in 10-30\% increases in levels of the AMPA receptor subunits. In contrast to the effects of WTS on AMPA receptor subunits, levels of the NMDA receptor subunits NR1, NR2A, and NR2B were unchanged after WTS and/or treatment with zVAD-fmk (Fig. 5d). Because zVAD-fmk can inhibit several different caspases, we performed an additional experiment in which we used a selective inhibitor of caspase-1 (z-WEHD-fmk) (Thornberry et al., 1997) and a selective inhibitor of caspase-3 (zDEVD-fmk) (Allen et al., 1999; Gastman et al., 1999). Both caspase inhibitors reduced GluR4 degradation, with zDEVD-fmk having a more pronounced effect (Fig. 5b).

Additional findings suggest that the caspase-mediated decrease in levels of AMPA receptor subunits after WTS is the result of caspase-mediated degradation of receptors, rather than being the result of selective loss of neurons expressing the subunits. First, we assessed levels of GluR4 by confocal analysis in cultures that had been subjected to WTS for $12 \mathrm{hr}$ and then resupplied trophic support for an additional $24 \mathrm{hr}$. Under these conditions very few neurons had died, and levels of activated caspases returned to near basal levels (Figs. 1, 2). Levels of GluR4 recovered to near basal levels after resupply of trophic support indicating that the process was reversible (Fig. 6). As was the case in the immunoblot analyses, zVAD-fmk prevented the decrease in levels of GluR4 immunoreactivity after WTS (Fig. 6).

\section{$\leftarrow$}

with Scheffe's post hoc tests). c, Hippocampal cultures were exposed to the indicated concentrations of glutamate for either $1 \mathrm{or} 5 \mathrm{hr}$; control cultures were exposed to saline for $5 \mathrm{hr}(\mathrm{Con})$. Levels of caspase activity were quantified, and values are the mean and SEM of determinations made in four cultures. 

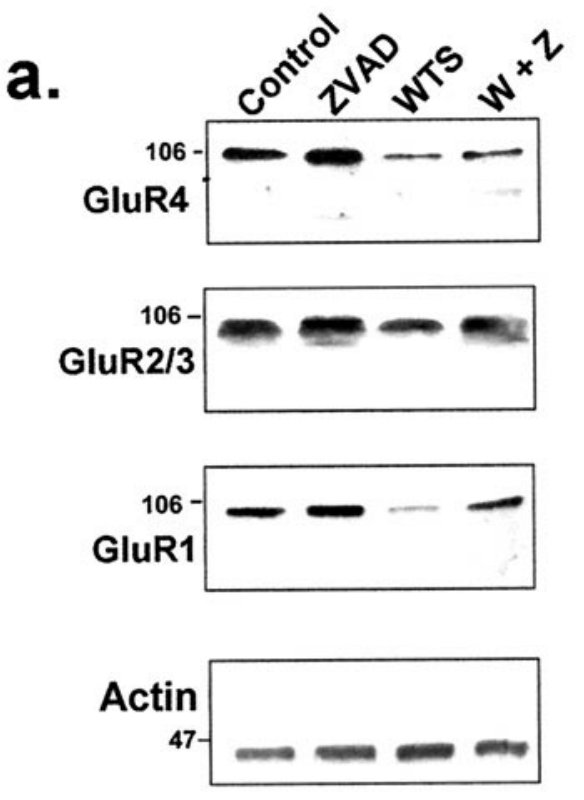

b.

GluR4

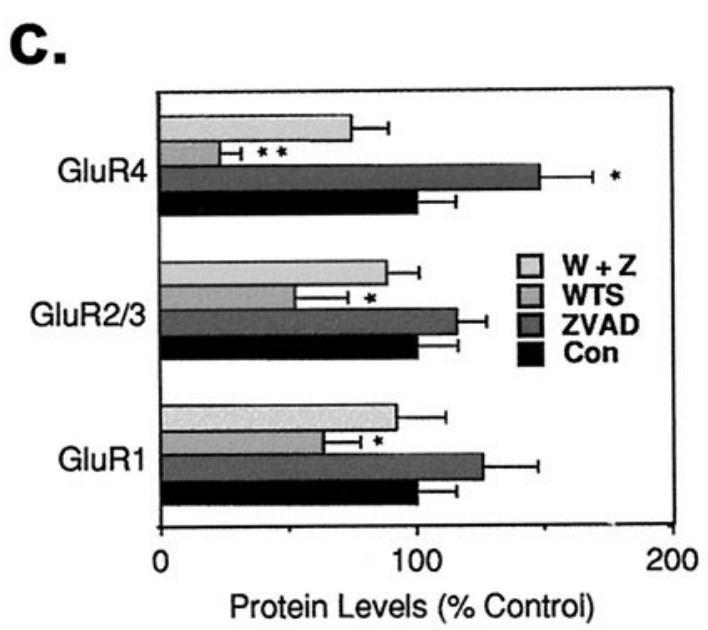

d.

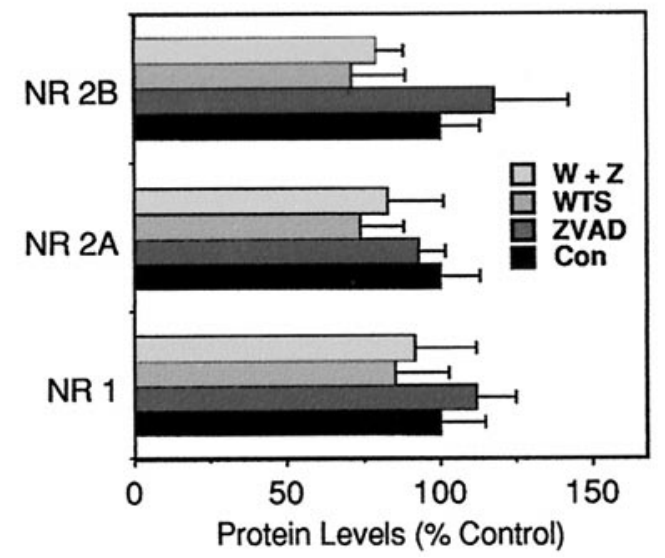

Figure 5. Evidence for selective caspase-mediated degradation of AMPA receptor subunits after withdrawal of trophic support. $a$, Immunoblots were performed on untreated control cortical cultures without (Control) or with zVAD-fmk (ZVAD), and cultures deprived of trophic support for 24 hr without $(W T S)$ or with zVAD-fmk $(W+Z)$, using antibodies against the indicated AMPA or NMDA receptor subunits, or an anti-actin antibody. $b$, Cultures were pretreated for $30 \mathrm{~min}$ with vehicle (control), $10 \mu \mathrm{M}$ zDEVD-fmk, or $10 \mu \mathrm{M}$ zWEHD-fmk. Cultures were then subjected to WTS for the indicated time points, and immunoblots were performed on cell lysates using anti-GluR4 antibody. $c, d$, Results of densitometric analyses of immunoblots; values are mean and SEM of three separate experiments. ${ }^{*} p<0.05,{ }^{* *} p<0.01$ compared with control cultures (ANOVA with Scheffe's post hoc tests).

To determine more directly the effect of caspase activity on AMPA receptor subunit levels, and to rule out the involvement of alterations in transcription and translation of the subunits, we performed studies in a cell-free system. We isolated membranes from rat cortical synaptosomes and then exposed them to cytosolic extracts from synaptosomes that had been treated with staurosporine, a potent inducer of caspase activation (Mattson et al., 1998). Before incubation with the membranes, cytoplasmic extracts were treated with either zVAD-fmk or vehicle. Immunoblot analysis showed that levels of GluR4 decreased markedly within $2 \mathrm{hr}$ of addition of activated cytoplasmic extract and reached a level $<20 \%$ of control values by $6 \mathrm{hr}$ (Fig. $7 a$ ). Treatment of activated extracts with $\mathrm{zVAD}$-fmk before incubation with synaptic membranes completely prevented the decrease in levels of GluR4, demonstrating a requirement for activated caspases. In contrast, levels of NR1 remained unchanged after addition of the activated cytoplasmic extract (Fig. 7b). Collectively, these data suggest that AMPA receptor subunits are selectively degraded in neurons undergoing apoptosis by a mechanism involving caspase activation.

\section{DISCUSSION}

Our data suggest that AMPA receptor subunits are targets of caspase-mediated degradation in neurons undergoing apoptosis. As evidence, we found that levels of full-length GluR1, GluR2/3, and GluR4 decreased markedly after WTS and exposure to staurosporine, two well established apoptotic stimuli in neurons. The decrease in levels of the AMPA receptor subunits was prevented by the caspase inhibitor zVAD-fmk. We found that the decrease in levels of full-length AMPA receptor subunits occurs rapidly (within 1-2 hr) in isolated synaptosomal membranes exposed to activated cytosolic extract, an effect blocked by zVADfmk, indicating that caspases induce degradation of AMPA receptor subunits rather than affect biosynthesis of the subunits. Indeed, data indicate that AMPA receptor subunits have long half-lives of $\sim 48 \mathrm{hr}$ (Perry and Henley, 1997). Caspase-mediated degradation of AMPA receptor subunits was reversed after resupply of trophic support in neurons subjected to WTS, indicating that receptor degradation was not simply a nonspecific conse- 
a.
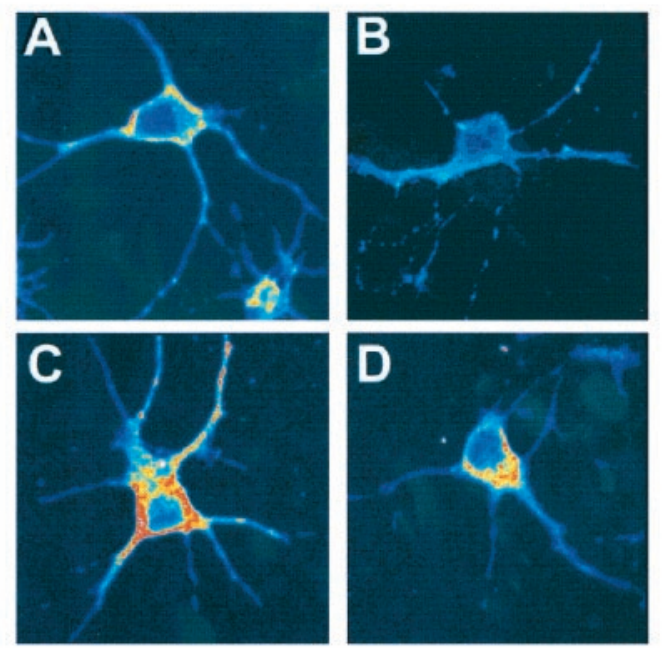

b.

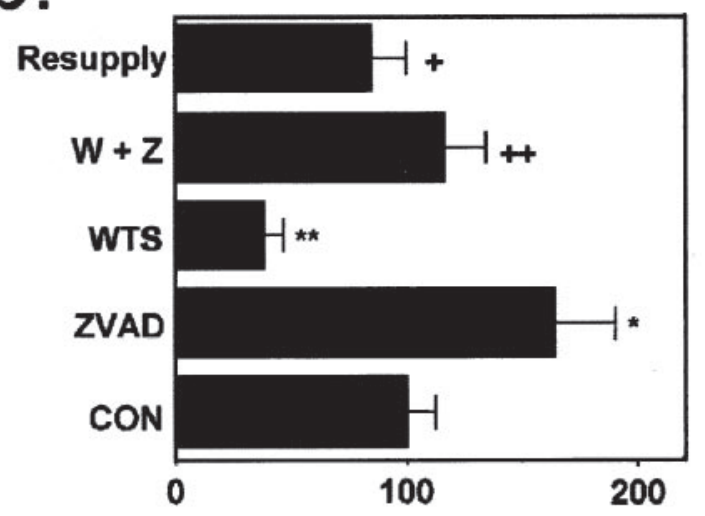

Fluorescence Intensity (arb. units)

Figure 6. Levels of GluR4 immunoreactivity are decreased in hippocampal neurons in a caspase-mediated manner, after withdrawal of trophic support. $a$, Representative confocal laser scanning microscope images of GluR4 immunoreactivity in a neuron in an untreated control hippocampal culture without $(A)$ or with $(C)$ zVAD-fmk, and cultures deprived of trophic support for $12 \mathrm{hr}(B)$ or deprived of trophic support for $12 \mathrm{hr}$, and then incubated in complete Neurobasal medium for an additional $24 \mathrm{hr}$ $(D) . b$, Levels of GluR4 immunoreactivity were quantified, and values are the mean and SEM of determinations made in four cultures (10-20 neurons assessed per culture). ${ }^{*} p<0.05,{ }^{* *} p<0.01$ compared with control value; ${ }^{+} p<0.05,{ }^{++} p<0.01$ compared with WTS value (ANOVA with Scheffe's post hoc tests).

quence of cell death. Our data suggest that the mechanism for reversal of caspase-mediated degradation of AMPA receptors after resupply of trophic support involves decreased levels of caspase activity and synthesis of new AMPA receptor subunits. It therefore appears that within a certain time window, caspase activation does not commit hippocampal neurons to death, a scenario consistent with previous studies of NGF withdrawalinduced death of sympathetic neurons (Deshmukh and Johnson, 1997). Levels of the NMDA receptor subunits NR1, NR2A, and NR2B were unchanged after WTS and/or exposure to zVAD, indicating that caspase activation results in selective degradation of AMPA receptors. This contrasts with calpains, which are
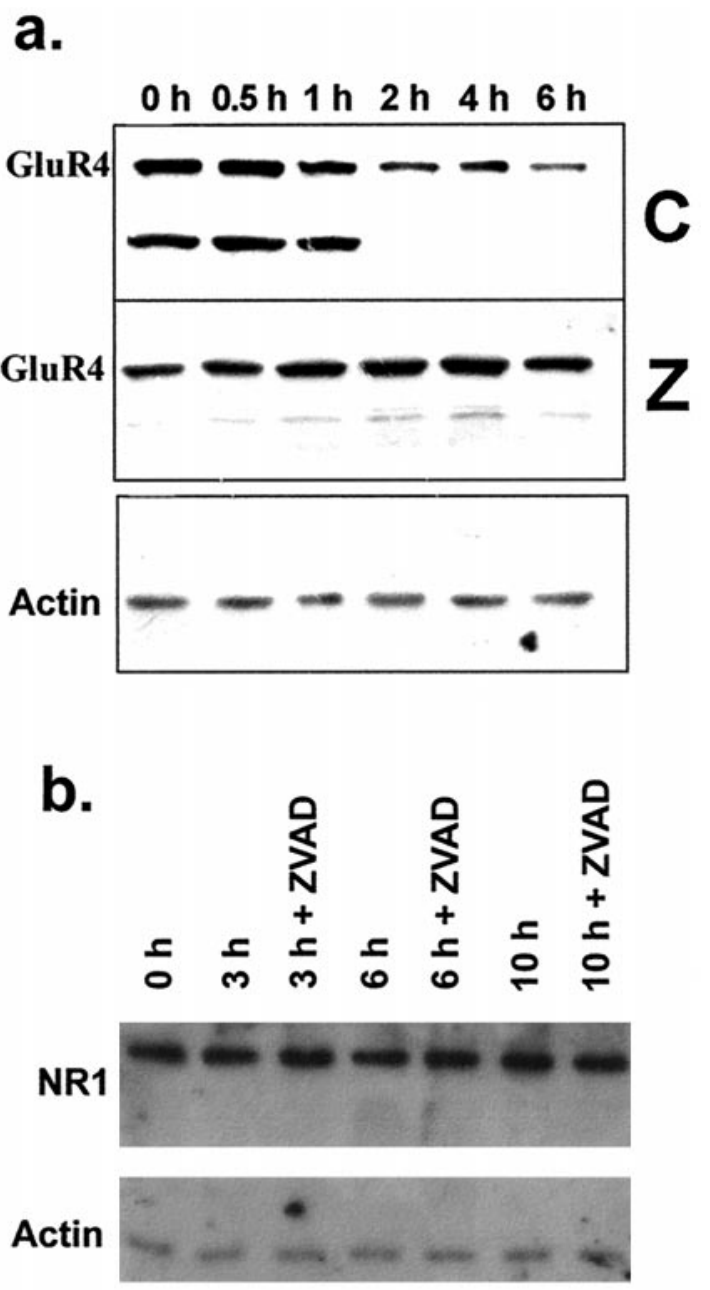

Figure 7. Caspase-mediated degradation of GluR4 in isolated synaptosomal membranes. Cortical synaptosomes were exposed to staurosporine (to activate caspases) for $2 \mathrm{hr}$, then cytoplasmic extracts prepared. These extracts were then added to synaptosomal membranes in the presence $(Z)$ or absence $(C)$ of zVAD-fmk and incubated at $37^{\circ} \mathrm{C}$. At the indicated time points, protein samples were subjected to Western blot analysis using antibodies against either GluR4 $(a)$ or NR1 $(b)$. Each blot was reprobed with an anti-actin antibody to confirm equal protein loading.

activated in neurons undergoing either apoptosis or necrosis and can degrade both NMDA and AMPA receptor subunits (Bi et al., 1996, 1997, 1998a,b). Thus, selective AMPA receptor subunit degradation is specifically associated with apoptosis and not necrosis.

Our confocal analysis demonstrating colocalization of activated caspase-3 and PSD95 suggests that activated caspase-3 is present in the appropriate subcellular compartment for access to AMPA receptor subunits. When taken together with recent studies that describe membrane-associated caspases (Krebs et al., 1999) and demonstrate that caspases can be activated locally in synaptic terminals (Mattson et al., 1998) and with data in the present study showing that caspases can cause degradation of AMPA receptor subunits in isolated synaptic membranes, the data strongly suggest that activated caspases can indeed degrade AMPA receptor subunits in vivo. There is certainly ample evidence that other membrane-associated proteins are cleaved by caspases in cells undergoing apoptosis, including spectrin, amyloid precursor protein, and presenilins (Martin et al., 1995; Kim et al., 1997; Barnes et al., 1998). 
An increasing number of proteins are being identified that are cleaved by caspases during the process of apoptosis (for review, see Chan and Mattson, 1999). Such caspase substrates include the DNA repair protein Ku (Ajmani et al., 1995), poly-ADP ribose polymerase (Lazebnik et al., 1994), actin and spectrin (Martin et al., 1995; Kayalar et al., 1996, Wang et al., 1998), gelsolin (Kamada et al., 1998), and presenilins (Kim et al., 1997). Several observations are consistent with the possibility that AMPA receptor subunits are direct substrates for caspases. First, we found that the caspase inhibitor zVAD-fmk prevented AMPA receptor subunit degradation in intact neurons subjected to apoptotic insults and in isolated synaptic membranes exposed to cytosolic extracts containing activated caspases. Second, each of the AMPA receptor subunits contains putative caspase cleavage sites (S. L. Chan and M. P. Mattson, unpublished data). Third, recent studies have shown that other membrane receptors are substrates for caspases, including a receptor for netrin-1 (Mehlen et al., 1998) and the T-cell receptor $\zeta$ chain in lymphocytes (Gastman et al., 1999). If caspases do indeed directly cleave AMPA receptor subunits, it seems likely that further rapid degradation of the subunits occurs because lower molecular weight cleavage products of the subunits were not typically present in our Western blot analyses. Previous studies have shown that cleavage of a protein by caspases can result in either generation of stable cleavage products or rapid degradation of the entire substrate protein, depending on the particular substrate (Chan and Mattson, 1999).

Data from our $\mathrm{Ca}^{2+}$ imaging and cell survival studies provide evidence for a role for caspase-mediated degradation of AMPA receptor subunits in modulating neuronal death responses to glutamate. Calcium responses to glutamate and neuronal vulnerability to excitotoxic necrosis were significantly decreased after WTS, and these alterations were largely prevented by treatment with the caspase inhibitor zVAD-fmk. On the other hand, our data indicate that caspase activation after WTS contributes to increased neuronal vulnerability to apoptosis induced by exposure to a low level of glutamate. We therefore propose that caspase-mediated cleavage of AMPA receptor subunits serves the function of "driving" neurons down an apoptotic pathway of cell death, thereby preventing necrosis. In this scenario, the membrane proteins (AMPA receptors) that control the intensity and duration of the "death signal" (calcium and sodium influx) are subject to a form of feedback modulation by an enzyme(s) (caspases) that acts as an executioner of the cell death process. This novel mechanism for controlling the mode of neuronal death is likely to be operative in various physiological and pathological settings in which activation of glutamate receptors plays a role, including programmed cell death during development of the nervous system (Caldero et al., 1997); death of cortical, striatal, and hippocampal neurons after cerebral ischemia (Linnik et al., 1995; Mattson et al., 1999); degeneration of hippocampal and cortical neurons in Alzheimer's disease (Su et al., 1994; Guo et al., 1998); and death of spinal cord motor neurons in amyotrophic lateral sclerosis (Rothstein, 1995; Kruman et al., 1999).

Because our data indicate that caspase activation and AMPA receptor subunit degradation are reversible processes, it should also be considered that caspase-mediated modulation of AMPA receptors may play a role in processes that are regulated by glutamate receptors, including developmental and synaptic plasticity (Mattson et al., 1989; Rajan and Cline, 1998; Wheal et al., 1998; Zamanillo et al., 1999). AMPA receptors are localized primarily in postsynaptic regions of dendrites. Recent studies have shown that activation of glutamate receptors results in local activation of caspases in such dendritic compartments (Mattson et al., 1998; Duan et al., 1999b). The present findings therefore suggest that one function of such localized caspase activation is to modulate postsynaptic responses to glutamate. Such a role for caspases would be consistent with emerging data from studies of non-neuronal cells showing that by cleaving specific signal transduction proteins, caspases can modify various signaling cascades. Examples include focal adhesion kinase (Gervais et al., 1998), the tyrosine kinase Fyn (Ricci et al., 1999), and protein kinase C isoforms (Khwaja and Tatton, 1999). In light of the complex signaling pathways involved in the regulation of neuronal survival and plasticity, it seems likely that many different signaling proteins will be identified that are subject to modification by caspases.

\section{REFERENCES}

Ajmani AK, Satoh M, Reap E, Cohen PL, Reeves WH (1995) Absence of autoantigen $\mathrm{Ku}$ in mature human neutrophils and human promyelocytic leukemia line (HL-60) cells and lymphocytes undergoing apoptosis. J Exp Med 181:2049-2058.

Allen JW, Knoblach SM, Faden AI (1999) Combined mechanical trauma and metabolic impairment in vitro induces NMDA receptor-dependent neuronal cell death and caspase-3-dependent apoptosis. FASEB J 13:1875-1882.

Ankarcrona M, Dypbukt JM, Bonfoco E, Zhivotovsky B, Orrenius S, Lipton SA, Nicotera P (1995) Glutamate-induced neuronal death: a succession of necrosis or apoptosis depending on mitochondrial function. Neuron 15:961-973.

Barnes NY, Li L, Yoshikawa K, Schwartz LM, Oppenheim RW, Milligan CE (1998) Increased production of amyloid precursor protein provides a substrate for caspase-3 in dying motoneurons. J Neurosci 18:5869-5880.

Bi X, Chang V, Molnar E, McIlhinney RA, Baudry M (1996) The C-terminal domain of glutamate receptor subunit 1 is a target for calpain-mediated proteolysis. Neuroscience 73:903-906.

Bi X, Chen J, Dang S, Wenthold RJ, Tocco G, Baudry M (1997) Characterization of calpain-mediated proteolysis of GluR1 subunits of alphaamino-3-hydroxy-5-methylisoxazole-4-propionate receptors in rat brain. J Neurochem 68:1484-1494.

Bi X, Chen J, Baudry M (1998a) Calpain-mediated proteolysis of GluR1 subunits in organotypic hippocampal cultures following kainic acid treatment. Brain Res 781:355-357.

Bi X, Rong Y, Chen J, Dang S, Wang Z, Baudry M (1998b) Calpainmediated regulation of NMDA receptor structure and function. Brain Res 790:245-253.

Caldero J, Ciutat D, Llado J, Castan E, Oppenheim RW, Esquerda JE (1997) Effects of excitatory amino acids on neuromuscular development in the chick embryo. J Comp Neurol 387:73-95.

Chan SL, Mattson MP (1999) Caspase and calpain substrates: roles in synaptic plasticity and cell death. J Neurosci Res 58:167-190.

Chan SL, Tammariello SP, Estus S, Mattson MP (1999) Prostate apoptosis response-4 mediates trophic factor withdrawal-induced apoptosis of hippocampal neurons: actions prior to mitochondrial dysfunction and caspase activation. J Neurochem 73:502-512.

Cheng B, Mattson MP (1991) NGF and bFGF protect rat and human central neurons against hypoglycemic damage by stabilizing calcium homeostasis. Neuron 7:1031-1041.

Cheng B, Furukawa K, O'Keefe JA, Goodman Y, Kihiko M, Fabian T, Mattson MP (1995) Basic fibroblast growth factor selectively increases AMPA-receptor subunit GluR1 protein level, and differentially modulates $\mathrm{Ca} 2+$ responses to AMPA and NMDA in hippocampal neurons. J Neurochem 65:2525-2536.

Choi DW (1992) Excitotoxic cell death. J Neurobiol 23:1261-1276.

Deshmukh M, Johnson Jr EM (1997) Programmed cell death in neurons: focus on the pathway of nerve growth factor deprivation-induced death of sympathetic neurons. Mol Pharmacol 51:897-906.

Doble A (1995) Excitatory amino acid receptors and neurodegeneration. Therapie 50:319-337.

Du Y, Bales KR, Dodel RC, Hamilton-Byrd E, Horn JW, Czilli DL, Simmons LK, Ni B, Paul SM (1997) Activation of a caspase 3-related cysteine protease is required for glutamate-mediated apoptosis of cultured cerebellar granule neurons. Proc Natl Acad Sci USA 94:11657-11662.

Duan W, Zhang Z, Gash DM, Mattson MP (1999a) Participation of Par-4 
in degeneration of dopaminergic neurons in primate and rodent models of Parkinson's disease. Ann Neurol 46:587-597.

Duan W, Rangnekar VM, Mattson MP (1999b) Prostate apoptosis response-4 production in synaptic compartments following apoptotic and excitotoxic insults: evidence for a pivotal role in mitochondrial dysfunction and neuronal degeneration. J Neurochem 72:2312-2322.

Gasic GP, Hollmann M (1992) Molecular neurobiology of glutamate receptors. Annu Rev Physiol 54:507-536.

Gastman BR, Johnson DE, Whiteside TL, Rabinowich H (1999) Caspasemediated degradation of $\mathrm{T}$-cell receptor zeta-chain. Cancer Res 59:1422-1427.

Gervais FG, Thornberry NA, Ruffolo SC, Nicholson DW, Roy S (1998) Caspases cleave focal adhesion kinase during apoptosis to generate a FRNK-like polypeptide. J Biol Chem 273:17102-17108.

Guo Q, Fu W, Xie J, Luo H, Sells SF, Geddes JW, Bondada V, Rangnekar VM, Mattson MP (1998) Par-4 is a mediator of neuronal degeneration associated with the pathogenesis of Alzheimer's disease. Nat Med 4:957-962.

Guo Q, Fu W, Sopher BL, Miller MW, Ware CB, Martin GM, Mattson MP (1999) Increased vulnerability of hippocampal neurons to excitotoxic necrosis in presenilin-1 mutant knockin mice. Nat Med 5:101-107.

Hara H, Friedlander RM, Gagliardini V, Ayata C, Fink K, Huang Z, Shimizu-Sasamata M, Yuan J, Moskowitz MA (1997) Inhibition of interleukin 1beta converting enzyme family proteases reduces ischemic and excitotoxic neuronal damage. Proc Natl Acad Sci USA 94:2007-2012.

Kamada S, Kusano H, Fujita H, Ohtsu M, Koya RC, Kuzumaki N, Tsujimoto YA (1998) A cloning method for caspase substrates that uses the yeast two-hybrid system: cloning of the antiapoptotic gene gelsolin. Proc Natl Acad Sci USA 95:8532-8537.

Kayalar C, Ord T, Testa MP, Zhong LT, Bredesen DE (1996) Cleavage of actin by interleukin $1 \beta$-converting enzyme to reverse DNase I inhibition. Proc Natl Acad Sci USA 93:2234-2238.

Keller JN, Pang Z, Geddes JW, Begley JG, Germeyer A, Waeg G, Mattson MP (1997) Impairment of glucose and glutamate transport and induction of mitochondrial oxidative stress and dysfunction in synaptosomes by amyloid $\beta$-peptide: role of the lipid peroxidation product 4-hydroxynonenal. J Neurochem 69:273-284.

Kennedy MB (1997) The postsynaptic density at glutamatergic synapses. Trends Neurosci 20:264-268.

Khwaja A, Tatton L (1999) Caspase-mediated proteolysis and activation of protein kinase Cdelta plays a central role in neutrophil apoptosis. Blood 94:291-301.

Kim TW, Pettingell WH, Jung YK, Kovacs DM, Tanzi RE (1997) Alternative cleavage of Alzheimer-associated presenilins during apoptosis by a caspase-3 family protease. Science 277:373-376.

Krebs JF, Armstrong RC, Srinivasan A, Aja T, Wong AM, Aboy A, Sayers R, Pham B, Vu T, Hoang K, Karanewsky DS, Leist C, Schmitz A, Wu JC, Tomaselli KJ, Fritz LC (1999) Activation of membrane-associated procaspase-3 is regulated by Bcl-2. J Cell Biol 144:915-926.

Krieglstein J, Lippert K, Poch G (1996) Apparent independent action of nimodipine and glutamate antagonists to protect cultured neurons against glutamate-induced damage. Neuropharmacology 35:1737-1742.

Kruman I, Pedersen WA, Mattson MP (1999) ALS-linked Cu/Zn-SOD mutation increases vulnerability of motor neurons to excitotoxicity by a mechanism involving increased oxidative stress and perturbed calcium homeostasis. Exp Neurol 160:28-39.

Larm JA, Cheung NS, Beart PM (1997) Apoptosis induced via AMPAselective glutamate receptors in cultured murine cortical neurons. J Neurochem 69:617-622.

Lazebnik YA, Kaufmann SH, Desnoyers S, Poirier GG, Earnshaw WC (1994) Cleavage of poly(ADP-ribose) polymerase by a proteinase with properties like ICE. Nature 371:346-347.

Li H, Yuan J (1999) Deciphering the pathways of life and death. Curr Opin Cell Biol 11:261-266.

Linnik MD, Zahos P, Geschwind MD, Federoff HJ (1995) Expression of bcl-2 from a defective herpes simplex virus-1 vector limits neuronal death in focal cerebral ischemia. Stroke 26:1670-1674.

Martin SJ, O'Brien GA, Nishioka WK, McGahon AJ, Mahboubi A, Saido TC, Green DR (1995) Proteolysis of fodrin (non-erythroid spectrin) during apoptosis. J Biol Chem 270:6425-6428.

Mattson MP, Murrain M, Guthrie PB, Kater SB (1989) Fibroblast growth factor and glutamate: opposing actions in the generation and degeneration of hippocampal neuroarchitecture. J Neurosci 9:3728-3740.

Mattson MP, Cheng B, Davis D, Bryant K, Lieberburg I, Rydel RE (1992)
$\beta$-Amyloid peptides destabilize calcium homeostasis, and render human cortical neurons vulnerable to excitotoxicity. J Neurosci 12:376-389.

Mattson MP, Kumar KN, Wang H, Cheng B, Michaelis EK (1993) Basic FGF regulates the expression of a functional $71 \mathrm{kDa}$ NMDA receptor protein that mediates calcium influx and neurotoxicity in hippocampal neurons. J Neurosci 13:4575-4588.

Mattson MP, Barger SW, Begley JG, Mark RJ (1995) Calcium, free radicals, and excitotoxic death in primary cell culture. Methods Cell Biol 46:187-216

Mattson MP, Keller JN, Begley JG (1998) Evidence for synaptic apoptosis. Exp Neurol 53:35-48.

Mattson MP, Culmsee C, Yu ZF (1999) Apoptotic and anti-apoptotic mechanisms in stroke. Cell Tissue Res, in press.

Mehlen P, Rabizadeh S, Snipas SJ, Assa-Munt N, Salvesen GS, Bredesen DE (1998) The DCC gene product induces apoptosis by a mechanism requiring receptor proteolysis. Nature 395:801-804.

Michaelis EK (1998) Molecular biology of glutamate receptors in the central nervous system and their role in excitotoxicity, oxidative stress and aging. Prog Neurobiol 4:369-415.

Oppenheim RW (1991) Cell death during development of the nervous system. Annu Rev Neurosci 14:453-501.

Perry MJ, Henley JM (1997) Half life analysis of the alpha-amino-3hydroxy-5-methyl-4- isoazolepropionate receptor subunit gluR1 in primary cultured rat cerebellar granule cells. Biochem Soc Trans 25:539S.

Rajan I, Cline HT (1998) Glutamate receptor activity is required for normal development of tectal cell dendrites in vivo. J Neurosci 18:7836-7846.

Ricci JE, Maulon L, Luciano F, Guerin S, Livolsi A, Mari B, Breittmayer JP, Peyron JF, Auberger P (1999) Cleavage and relocation of the tyrosine kinase P59F YN during Fas-mediated apoptosis in T lymphocytes. Oncogene 18:3963-3969.

Rothstein JD (1995) Excitotoxicity and neurodegeneration in amyotrophic lateral sclerosis. Clin Neurosci 3:348-359.

Schierle GS, Brundin P (1999) Excitotoxicity plays a role in the death of tyrosine hydroxylase-immunopositive nigral neurons cultured in serumfree medium. Exp Neurol 157:338-348.

Seeburg PH (1993) The TIPS/TINS lecture, the molecular biology of mammalian glutamate receptor channels. Trends Pharmacol Sci 14:297-303.

Staton PC, Bristow DR (1997) The dietary excitotoxins beta- $N$-methylamino-L-alanine and beta- $N$-oxalylamino-L-alanine induce necrotic- and apoptotic-like death of rat cerebellar granule cells. J Neurochem 69:1508-1518.

Su JH, Anderson AJ, Cummings B, Cotman CW (1994) Immunocytochemical evidence for apoptosis in Alzheimer's disease. NeuroReport 5:2529-2533.

Tatton NA, Maclean-Fraser A, Tatton WG, Perl DP, Olanow CW (1998) A fluorescent double-labeling method to detect and confirm apoptotic nuclei in Parkinson's disease. Ann Neurol 44:S142-S148.

Tenneti L, D'Emilia DM, Troy CM, Lipton SA (1998) Role of caspases in $\mathrm{N}$-methyl-D-aspartate-induced apoptosis in cerebrocortical neurons. J Neurochem 71:946-959.

Thornberry NA (1997) The caspase family of cysteine proteases. Br Med Bull 53:478-490.

Thornberry NA, Rano TA, Peterson EP, Rasper DM, Timkey T, GarciaCalvo M, Houtzager VM, Nordstrom PA, Roy S, Vaillancourt JP, Chapman KT, Nicholson DW (1997) A combinatorial approach defines specificities of members of the caspase family and granzyme B. Functional relationships established for key mediators of apoptosis. J Biol Chem 272:17907-17911.

Wang KK, Posmantur R, Nath R, McGinnis K, Whitton M, Talanian RV, Glantz SB, Morrow JS (1998) Simultaneous degradation of alphaII- and betaII-spectrin by caspase 3 (CPP32) in apoptotic cells. J Biol Chem 273:22490-22497.

Wheal HV, Chen Y, Mitchell J, Schachner M, Maerz W, Wieland H, Van Rossum D, Kirsch J (1998) Molecular mechanisms that underlie structural and functional changes at the postsynaptic membrane during synaptic plasticity. Prog Neurobiol 55:611-640.

Xi D, Ramsdell JS (1996) Glutamate receptors and calcium entry mechanisms for domoic acid in hippocampal neurons. NeuroReport 7:1115-1120.

Zamanillo D, Sprengel R, Hvalby O, Jensen V, Burnashev N, Rozov A, Kaiser KM, Koster HJ, Borchardt T, Worley P, Lubke J, Frotscher M, Kelly PH, Sommer B, Andersen P, Seeburg PH, Sakmann B (1999) Importance of AMPA receptors for hippocampal synaptic plasticity but not for spatial learning. Science 284:1805-1811. 